\title{
The Sigma 2 receptor promotes and the Sigma 1 receptor inhibits mu-opioid receptor-mediated antinociception
}

\author{
Pilar Sánchez-Blázquez ${ }^{1 *} \mathbb{0}$, Elsa Cortés-Montero ${ }^{1}$, María Rodríguez-Muñoz ${ }^{1}$, Manuel Merlos² \\ and Javier Garzón-Niño'
}

\begin{abstract}
The Sigma-1 receptor ( $\sigma 1 \mathrm{R})$ has emerged as an interesting pharmacological target because it inhibits analgesia mediated by mu-opioid receptors (MOR), and also facilitates the development of neuropathic pain. Based on these findings, the recent cloning of the Sigma-2 receptor ( $\sigma 2 R)$ led us to investigate its potential role as a regulator of opioid analgesia and of pain hypersensitivity in $\sigma 2 R$ knockout mice. In contrast to $\sigma 1 R$ deficient mice, $\sigma 2 R$ knockout mice developed mechanical allodynia following establishment of chronic constriction injury-induced neuropathic pain, which was alleviated by the $\sigma 1$ R antagonist S1RA. The analgesic effects of morphine, [D-Ala, N-MePhe, Glyol]-encephalin (DAMGO) and $\beta$-endorphin increased in $\sigma 1 \mathrm{R}^{-/-}$mice and diminished in $\sigma 2 \mathrm{R}^{-/-}$mice. The analgesic effect of morphine was increased in $\sigma 2 \mathrm{R}^{-/-}$mice by treatment with S1RA. However, $\sigma 2 \mathrm{R}^{-1-}$ mice and wild-type mice exhibited comparable antinociceptive responses to the delta receptor agonist [D-Pen2,5]-encephalin (DPDPE), the cannabinoid type 1 receptor agonist WIN55,212-2 and the a2-adrenergic receptor agonist clonidine. Therefore, while $\sigma R 1$ inhibits and $\sigma 2 R$ facilitates MOR-mediated analgesia these receptors exchange their roles when regulating neuropathic pain perception. Our study may help identify new pharmacological targets for diminishing pain perception and improving opioid detoxification therapies.
\end{abstract}

Keywords: Sigma 2 receptor, Sigma 1 receptor, Knockout mice, Mu opioid receptor, Neuropathic pain, Analgesia

\section{Introduction}

Sigma receptors $(\sigma \mathrm{Rs})$ are unique transmembrane proteins expressed throughout the central nervous system and in certain peripheral tissues. Based on current classifications, there are two types of these receptors, namely, the sigma-1 receptor $(\sigma 1 \mathrm{R})$ and the sigma-2 receptor $(\sigma 2 R)[1-4]$. The $\sigma 1 R$ was initially identified in 1976 as a member of the plasma membrane opioid receptor family [5], while $\sigma 2 \mathrm{R}$ was not discovered until later. For many years, $\sigma$ Rs were described to bind to radioligands in preparations of brain synaptosomes. $\left[{ }^{3} \mathrm{H}\right](+)$-pentazocine

*Correspondence: psb@cajal.csic.es

${ }^{1}$ Neuropharmacology, Cajal Institute, Consejo Superior de Investigaciones Científicas (CSIC), Doctor Arce 37, 28002 Madrid, Spain

Full list of author information is available at the end of the article exhibits a high affinity for $\sigma 1 \mathrm{R}$, whereas $\left[{ }^{3} \mathrm{H}\right] \mathrm{DTG}$ binds with equal affinity to both $\sigma 1 R$ and $\sigma 2 R$. Subsequent studies have revealed that these proteins are also involved in intracellular ion regulation and neuron survival $[1,4$, 6-8].

The $\sigma 1 \mathrm{R}$ was purified, sequenced and cloned from guinea pig brain in 1996, and it bears little sequence homology to any known mammalian receptor [9]. On the other hand, it has been postulated that $\sigma 2 \mathrm{R}$ complexes with progesterone receptor membrane component 1 (PGRMC1). The recent molecular cloning of $\sigma 2 \mathrm{R}$ identified this protein as the TMEM97 protein [10-12]. Some evidence suggest that $\sigma 2 \mathrm{R}$ is also involved in cholesterol trafficking and homeostasis [13] and in the regulation of intracellular calcium levels [14]. Notably, $\sigma 2 \mathrm{R}$ is involved in several disease states, and the utility of its original author(s) and the source, provide a link to the Creative Commons licence, and indicate if changes were made. The images or other third party material in this article are included in the article's Creative Commons licence, unless indicated otherwise in a credit line to the material. If material is not included in the article's Creative Commons licence and your intended use is not permitted by statutory regulation or exceeds the permitted use, you will need to obtain permission directly from the copyright holder. To view a copy of this licence, visit http://creativecommons.org/licenses/by/4.0/. The Creative Commons Public Domain Dedication waiver (http://creativeco mmons.org/publicdomain/zero/1.0/) applies to the data made available in this article, unless otherwise stated in a credit line to the data. 
exogenous ligands as cancer therapeutics and diagnostic tools has been reported [15-17]. Additionally, $\sigma 2 \mathrm{R}$ has been implicated in multiple neurodegenerative and neurological disorders $[18,19]$. Similar to the ligands of $\sigma 1 R$, certain molecules that bind to $\sigma 2 \mathrm{R}$ also reduce mechanical hypersensitivity in a spared nerve injury model [20].

The availability of $\sigma 2 R^{-1-}$ ( $\sigma 2 R$ knockout) mice, deficient in TMEM $97 / \sigma 2 R$, have allowed us to investigate the potential role of this receptor in pain sensitivity. Because $\sigma 1 \mathrm{R}$ participate in a tonic anti-opioid system [21, 22], we also evaluated the capacity of $\sigma 2 R$ to modulate opioid induced analgesia. We observed that $\sigma 2 \mathrm{R}$-deficient mice do not exhibit overt physical or behavioral abnormalities. Most importantly, we found that $\sigma 2 R$ contributes to the analgesic effects of MOR agonists but not those of delta opioid or cannabinoid type 1 receptor agonists.

\section{Materials and methods Animals and drugs}

Male albino CD-1 mice (ENVIGO, Barcelona, Spain), wild-type (WT) mice, $\sigma 2 \mathrm{R}^{-1-}$ (allele name Tmem97tm1.1(KOMP)Vlcg) and $\sigma 1 \mathrm{R}^{-1-}$ mice were used in the study. The genetically modified $\sigma 2 \mathrm{R}^{-1-}$ mice were on the C57BL/6NTac background and were originally purchased from UC Davis KOMP Repository (MMRRC Stock \#: 050148-UCD, Davis, CA, USA). $\sigma 1 \mathrm{R}^{-/-}$mice were backcrossed (N10 generation) onto a CD1 albino genetic background were obtained from (ENVIGO, Milano, Italy). The mice used in these experiments were produced from heterozygous breeding pairs and assigned randomly to be used for the different experiments. The $\sigma 2 \mathrm{R}^{-1-}$ mice exhibited no noticeable differences from their WT littermates with respect to appearance, body size, or morphologic parameters. The genotypes of the WT and $\sigma 2 \mathrm{R}^{-1-}$ mice were confirmed by PCR. Each DNA sample was amplified using two sets of primers and a PCR thermocycler (Eppendorf Iberica SLU, Madrid, Spain). One set of primers consisted of Reg-Tmem97wtF (AGAGTAAAGGGCTAGCCAGGAAACC) and Reg-Tmem97-wtR (GGTGTCACACACCTTTAATCC CAGC). This set was responsible for amplifying the WT sequence (320 bp). The second set consisted of Reg-LacF (ACTTGCTTTAAAAAACCTCCCACA) and RegTmem97-R (TCCTTCCCTGTAACCCATTTCTGGC). This set of PCR primers was responsible for amplifying the deleted sequence $(722 \mathrm{bp})$. Each DNA sample was run with both sets of primers (Sigma-Aldrich, Madrid, Spain) to determine whether the mice were WT, $\sigma 2 \mathrm{R}^{-1-}$ or heterozygous. The PCR thermal cycling protocol included two steps. The first step was as follows: denaturation at $94{ }^{\circ} \mathrm{C}$ for $15 \mathrm{~s}$ followed by $65^{\circ} \mathrm{C}$ for $30 \mathrm{~s}$ and then $72{ }^{\circ} \mathrm{C}$ for $40 \mathrm{~s}$. This series was repeated for 10 cycles, with the second temperature decreasing by $1{ }^{\circ} \mathrm{C}$ each cycle.
Directly following the first step, the second step was performed as follows: denaturation at $94{ }^{\circ} \mathrm{C}$ for $15 \mathrm{~s}$ followed by $55^{\circ} \mathrm{C}$ for $30 \mathrm{~s}$ and $72{ }^{\circ} \mathrm{C}$ for $40 \mathrm{~s}$. The second step was repeated for 30 cycles, and a final elongation at $72{ }^{\circ} \mathrm{C}$ for 5 min was performed.

All mouse housing, breeding and experimental protocols were performed in strict accordance with the guidelines of the European Community for the Care and Use of Laboratory Animals (Council Directive 2010/63/EU) and Spanish law (RD53/2013) regulating animal research. The use of drugs, experimental design and sample size determination were approved by the Ethical Committee for Research of the CSIC (SAF2015-65420 \& CAM PROEX 225/14). The mice were maintained at $22{ }^{\circ} \mathrm{C}$ on a diurnal 12-h light/dark cycle and provided free access to food and water. Male mice were specifically selected to avoid the potentially confounding variable of the female estrus cycle. To reduce the risk of social stress, mice from the same litter were grouped together and remained in these groups throughout the study. The mice were also provided extra space for comfort, as well as nesting material (e.g., soft paper and cardboard refuge) and small pieces of chewable wood. The experiments were performed in different cohorts of mice to avoid any variations caused by handling stress. The mice were used when they were between the ages of 6 and 10 weeks. All attempts were made to minimize the number of mice used in each experiment.

\section{Behavioral outcomes}

Before behavioral testing began, we allowed the mice to familiarize themselves with the testing room for two consecutive days $(60 \mathrm{~min} /$ day $)$. On the day of testing, we transferred the mice to the testing room $30 \mathrm{~min}$ prior to the test session. To prevent potential changes in behavior, we performed each test on a different cohort of animals. Initial screening included body weight and contact-righting reflex measurements.

Exploratory behavior. This test was performed in a $14 \times 14$ inch arena with a lattice containig 16 holes in the floor (Cibertec, Madrid, Spain). The arena was fitted with photocells to count the number of hole pokes during each $10 \mathrm{~min}$ trial. In addition, rearing, center activity, and peripheral activity were also recorded. A variation in exploratory behavior was defined as a change in the number of hole pokes without a change in the other activities.

\section{Spontaneous activity}

The mice were tested individually using $20 \mathrm{~cm} \times 20 \mathrm{~cm} \times 28 \mathrm{~cm}$ transparent plastic automated activity monitors (Accuscan activity analyzer -Versamax 260 v2.4; Omnitech Electronics, Inc., OH, USA). Infrared beam crossings were recorded for $100 \mathrm{~min}$ at $10 \mathrm{~min}$ 
intervals. At the end of each session, the mice were returned to their home cages, and the boxes were wiped clean with a $10 \%$ alcohol solution.

\section{Rota-Rod}

Motor coordination was measured using an accelerated rotarod (Ugo Basile). Each animal was trained to use the rotarod at a constant acceleration over six 5 min sessions with an interval of $20 \mathrm{~min}$ between trials. On the following days, the mice were again tested, and the time to fall from the rod was measured with a cutoff time of $5 \mathrm{~min}$.

\section{Passive avoidance task}

The acquisition and retention of passive avoidance behaviors were examined using identical illuminated and non-illuminated $\left(20 \mathrm{~cm}^{3} \times 10 \mathrm{~cm}^{3} \times 15 \mathrm{~cm}^{3}\right)$ boxes separated by a guillotine door $\left(5 \mathrm{~cm}^{2} \times 5 \mathrm{~cm}^{2}\right)$ as previously described [23]. Each mice participated in two separate trials. First, in the acquisition trial, each mouse was initially placed in the light compartment, and the door between the two compartments was opened after $10 \mathrm{~s}$. When the mouse entered the dark compartment, the guillotine door automatically closed, and an electrical foot shock $(0.5 \mathrm{~mA}, 3 \mathrm{~s})$ was delivered through the floor. The latency time to enter the dark chamber was recorded. Only mice that entered the dark chamber within $60 \mathrm{~s}$ were subjected to a retention trial. For the retention trial, each mouse was again placed in the light compartment, and the latency to enter the dark compartment was recorded (up to $10 \mathrm{~min}$ ).

\section{Nerve injury pain model}

After the basal mechanical sensitivity of the mice was tested, neuropathic pain was induced by chronic sciatic nerve constriction injury (CCI) surgery under isoflurane/ oxygen anesthesia [24] using the procedure described by Bennett and Xie [25] a modifications. Briefly, a $0.5 \mathrm{~cm}$ incision was made in the right midthigh, the biceps femoris muscle was separated, and the sciatic nerve was exposed proximal to its trifurcation. Two ligatures (5/0 braided silk suture; Lorca Marin, Murcia, Spain, 70,014 ) were tied around this nerve approximately $1 \mathrm{~mm}$ apart until a short flick of the ipsilateral hind limb was observed. The incision was then closed in layers with a 4-0 Ethicon silk suture. The same procedure was used for sham surgery except that the sciatic nerve was exposed but not ligated. The tactile pain threshold of both the ipsilateral and contralateral hind paws were then assessed on days $0,3,7$, and 12 post-surgery. The mice were individually placed in a transparent plastic cage with a wire mesh bottom that allowed full access to the paws. After a habituation period of $20 \mathrm{~min}$, a mechanical stimulus was delivered to the plantar surface from below the floor of the test chamber to measure allodynia using an automatic von Frey apparatus (Ugo Basile \#37,450, Comerio, Italy). A steel rod ( $0.5 \mathrm{~mm}$ diameter) was pushed against the hind paw over a $10 \mathrm{~s}$ period as the force increased from 0 to $10 \mathrm{~g}$. When the mouse withdrew its hind paw, the mechanical stimulus was automatically stopped, and the force at which withdrawal occurred was recorded. At each time point, three separate threshold measurements were obtained from each hind paw and then averaged.

\section{Evaluation of antinociception and acute tolerance}

The response of the animals to nociceptive stimuli was determined by the warm water $\left(52{ }^{\circ} \mathrm{C}\right)$ tail-flick test as previously described $[22,26]$. In this tail-flick analgesic test, a thermal noxious stimulus is applied to promote flicking of the mouse's tail, and opioids given intracerebroventricularly (icv) increase the time elapsed between application of the stimulus and the flick. This response involves a spinal reflex that is facilitated by the brain stem nociceptive modulating network. Baseline latencies ranged from 1.6 to $2.1 \mathrm{~s}$. A cut-off time of $10 \mathrm{~s}$ was used to minimize the risk of tissue damage. Drugs were icv injected into the lateral ventricles in a volume of $4 \mu \mathrm{L}$, and antinociception was assessed at different time intervals thereafter. Saline was likewise administered as a control. Antinociception is expressed as a percentage of the maximum possible effect $(\mathrm{MPE}=100 \times$ [test latencybaseline latency]/[cut-off time (10 s)-baseline latency]).

The development of morphine acute tolerance was monitored when a priming dose of $10 \mathrm{nmol}$ (WT mice) or $30 \mathrm{nmol}\left(\sigma 2 \mathrm{R}^{-1-}\right.$ mice) had no effect on baseline latencies. Thus, $24 \mathrm{~h}$ later, a test dose of morphine was injected icv and analgesia was measured at the post-injection interval of $30 \mathrm{~min}$.

The compounds used were morphine sulfate (Merck, Darmstadt, Germany); $\beta$-endorphin (GenScript, USA); DAMGO (\#1171, Tocris); DPDPE (\#1431, Tocris); WIN55,212-2 (\#1038, Tocris); clonidine (\#0690, Tocris). S1RA: 4-[2-[[5-methyl-1-(2-naphthalenyl)-1Hpyrazol-3-yl]oxy]ethyl] morpholine), was obtained from Esteve Pharmaceuticals (Barcelona, Spain). To facilitate selective and direct access to their targets, the compounds were each injected into the lateral ventricles of mice in a volume of $4 \mu \mathrm{L}$ volume as previously described [22, 26]. The animals were lightly anesthetized, and the drugs were injected icv $2 \mathrm{~mm}$ lateral and $2 \mathrm{~mm}$ caudal from bregma, and at a depth of $3 \mathrm{~mm}$ with a $10 \mu \mathrm{L}$ Hamilton syringe. The drugs were infused at a rate of $1 \mu \mathrm{L}$ every $5 \mathrm{~s}$. After that, the needle was maintained for an additional $10 \mathrm{~s}$. Eight to 10 mice were treated with each compound. Test drugs were dissolved in saline, and the doses and treatment intervals were selected based on previous studies and pilot assays. The 
motor performance of mice administered the solvents used was identical to non-injected animals.

In a series of experiments, the expression of $\sigma 2 R$ was reduced by subchronic administration of synthetic endcapped phosphorothioate antisense oligodeoxy-nucleotides (Sigma-Aldrich, Spain, USA). The ODN $\sigma 2 \mathrm{R}$ was $5^{\prime} \mathrm{A}^{*} \mathrm{C}^{*}$ GACTGGCAAGCCGGTGAT*A*G 3' (adapted from [27]). A random ODN (ODN RD) served as a control $[26,28]$. The animals were injected with either the vehicle, ODN RD or antisense oligodeoxynucleotide into the right lateral ventricle over a 5 day period. On day 6 , the analgesic compounds were injected icv, and the antinociceptive activity evaluated.

\section{Reverse-transcription (RT)-PCR}

Total RNA was isolated by using TRIzol Reagent (Invitrogen, USA) and first-strand cDNA was prepared from total RNA with an oligo(dT) 18 primer and AMV reverse transcriptase (BioFlux, Japan) according to the manufacturer's instructions. The primers used for subsequent PCR were, $\sigma 2 \mathrm{R}$ : 5'-GCGTGCGATCGC CGGGGCCCTGGCAGCTAGGC-3' (forward) and 5'-TTG TGT TTAAACTTT TTTCTT TCT TTTCTC CTCATACTTGT-3 (reverse); б1R: 5'-ATTGGCGAT CGCCCCGTGGGCCGCGGGACGG-3' (forward) and $5{ }^{\prime}$-ATTAGTTTAAACGGAGTCTTGGCCAAA GAGGTAG-3'(reverse); HINT1: 5'-GGCTGCGAT CGCCGCTGACGAGATTGCCAAG-3' (forward) and 5' - GTCGGTTTAAACACCAGGAGGCCAGTTCAT CT-3' (reverse); MOR: 5'-AGGAGCGATCGCCGC TGTATTTATTGTCTGCTGGACC-3' (forward) and 5'-GCGAGTTTAAACGGGCAATGGAGCAGTTTC TGCTT-3' (reverse); GAPDH: 5'-CATCACCATCTT CCAGGAGC-3' (forward) and 5'-ATCACAAACATG GGGGCATCG-3' (reverse). The PCR products were electrophoresed on $2 \%$ agarose gel, stained with ethidium bromide, and visualized under UV illumination. The intensities of the specific bands were analyzed and quantified.

\section{Statistical analysis}

Graphs were constructed and statistical analyses were performed using Sigmaplot v.14 (SPSS Science Software). The data were analyzed using 2-way ANOVA with genotype and treatment as main factors. A significant interaction was detected for all experiments, and the follow-up analysis involved 1-way ANOVAs for each genotype and treatment followed by all pairwise Holm-Sidak multiple comparison tests, as indicated in the figure legends. Statistical significance was defined as $p<0.05$.

\section{Results}

\section{Characterization of $\sigma 2 R^{-l-}$ mice}

We confirmed that $\sigma 2 \mathrm{R}^{-/-}$mice (KOMP Repository, MMRRC Stock \#: 050148-UCD, Davis, CA, USA) did not express $\sigma 2 R$ mRNA in brain tissue (Fig. 1a). Targeted deletion of the $\sigma 2 R$ gene was not accompanied by compensatory changes in the levels of mRNAs encoding critical proteins in our study, such as $\sigma 1 \mathrm{R}, \mathrm{MOR}$ or MOR- and $\sigma 1 \mathrm{R}$-regulated histidine triad nucleotide-binding protein
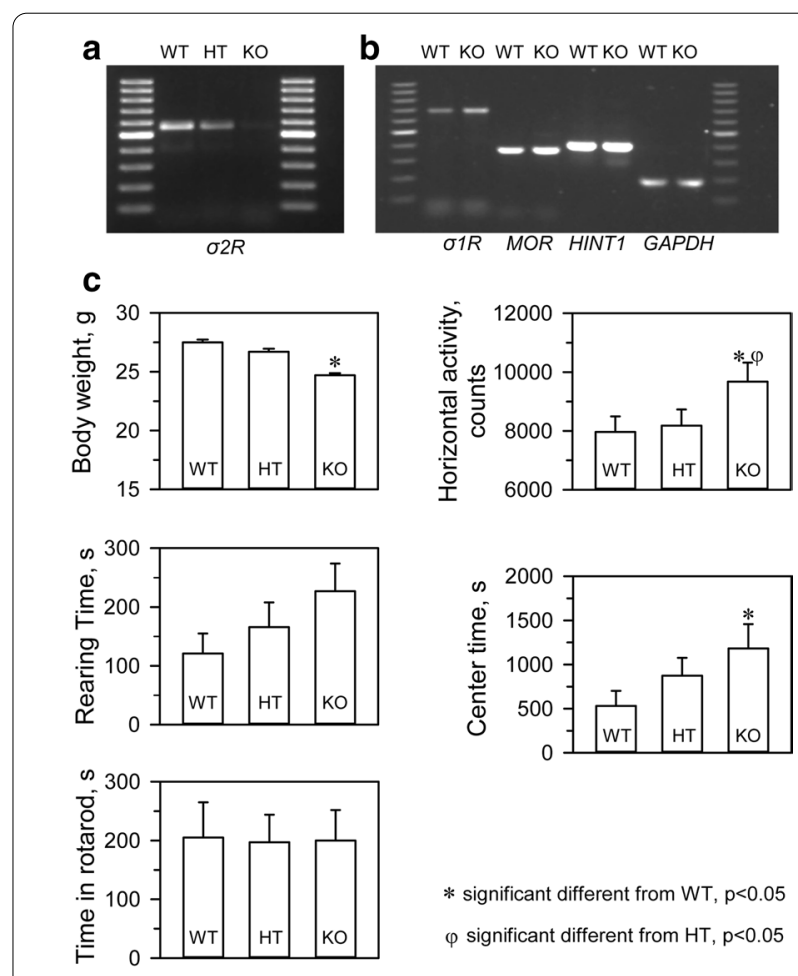

* significant different from WT, $p<0.05$ $\varphi$ significant different from $\mathrm{HT}, \mathrm{p}<0.05$

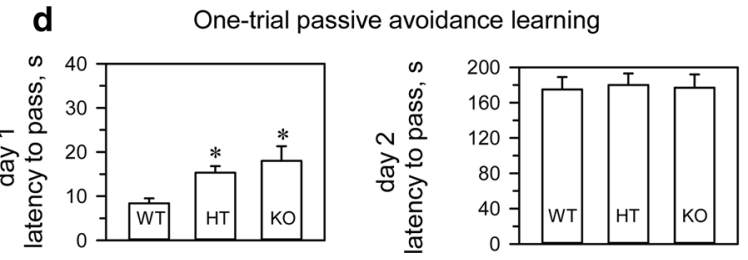

Fig. 1 Analysis of mRNA levels and phenotypic evaluation of transgenic mice. a PCR analysis of a litter from a single mating showing wild-type (WT) $(+/+)$, heterozygous (HT) $(+/-)$, and homozygous (-/-) $\sigma 2 R$ mice. $\mathbf{b}$ Deletion of $\sigma 2 R$ did not significantly alter the expression of $\sigma 1 R$, HINT1 or MOR. $\mathbf{c}$ Body weight gain in grams, horizontal activity, rearing time in seconds, and latency to fall from the rotarod in seconds for the three groups of mice. $\mathbf{d}$ Learning performance in the passive avoidance test. Six to eight mice (5 weeks of age) were subjected to each treatment, and the data represent the means \pm SEMs. * Indicates significantly different from the WT mice, degrees of freedom $(\mathrm{df})=16$, all data were analyzed by pairwise Holm-Sidak multiple comparison tests following ANOVA, $p<0.05$. $\sigma 1 R$, HINT1 and MOR represents sigma type 1 receptor, histidine triad nucleotide-binding protein 1 , and mu-opioid receptor, respectively 
1 (HINT1) (Fig. 1b). б2R-deficient mice bred normally and did not present evident physical or behavioral abnormalities at birth. At weaning (3 to 6 weeks old), $\sigma 2 \mathrm{R}^{-1-}$ mice were smaller than WT mice $(p<0.05)$. However, by week 8 , the differences in body weight were no longer significant. The locomotor performance of the mice was then evaluated by analyzing three basic parameters: horizontal activity, time spent in the center area, and rearing. While $\sigma 2 \mathrm{R}^{-1-}$ mice exhibited a similar exploratory behavior and rearing activity as control, they exhibited increased activity and spent more time in the center area (Fig. 1c). The motor coordination of both groups of mice was comparable when evaluated with an accelerating rotarod.

The WT and $\sigma 2 \mathrm{R}^{-1-}$ mice were also subjected to an inhibitory avoidance paradigm that tests cognition/ memory. A retention trial was conducted $24 \mathrm{~h}$ after the training trial. No significant differences were observed between WT and $\sigma 2 \mathrm{R}^{-/-}$mice in the retention trial. It should be noted that both groups did show an increase in latency in the retention trial compared to the training trial, which was interpreted as learning (Fig. 1d).

\section{Chronic constriction injury in WT and $\sigma 2 R^{-l-}$ mice}

Mice with CCI-induced neuropathic pain display a series of behavioral and molecular changes that are diminished upon treatment with antiallodynic substances such as $\sigma 1 \mathrm{R}$ antagonists [29]. Thus, we assessed the possible relevance of $\sigma 2 R$ in the development of neuropathic pain. Nerve-injured WT and $\sigma 2 \mathrm{R}^{-1-}$ mice maintained a healthy appearance and were well groomed. The body weights of both groups of mice decreased after surgery but returned to preoperative values within 2-4 days. Before surgery (day 0 ), WT and $\sigma 2 \mathrm{R}^{-1-}$ mice displayed similar responses to the mechanical nociceptive stimulus (Fig. 2). Seven days after surgery, sham-operated and CCI-exposed $\sigma 2 \mathrm{R}^{-1-}$ mice displayed similar responses of the contralateral paw as WT animals. On the other hand, from 1 to 7 days after surgery both groups of CCI mice showed identical levels of allodynia in the ipsilateral nerve-injured legs, and on days 12 to 15 , the nociceptive responses of both groups of CCI mice returned to presurgery levels. Icv administered S1RA (E-52862), a highly selective $\sigma 1 \mathrm{R}$ antagonist [30], reduced the allodynia induced by the CCI model in WT and $\sigma 2 \mathrm{R}^{-/-}$mice. The peak antiallodynic effect was observed $60 \mathrm{~min}$ after the administration of S1RA (Fig. 2).

\section{Influence of $\sigma 2 R$ on the antinociceptive response to morphine}

Icv administered morphine produces a dose-dependent antinociceptive effect when evaluated by the thermal tail-flick test (Fig. 3). In WT mice, the antinociceptive
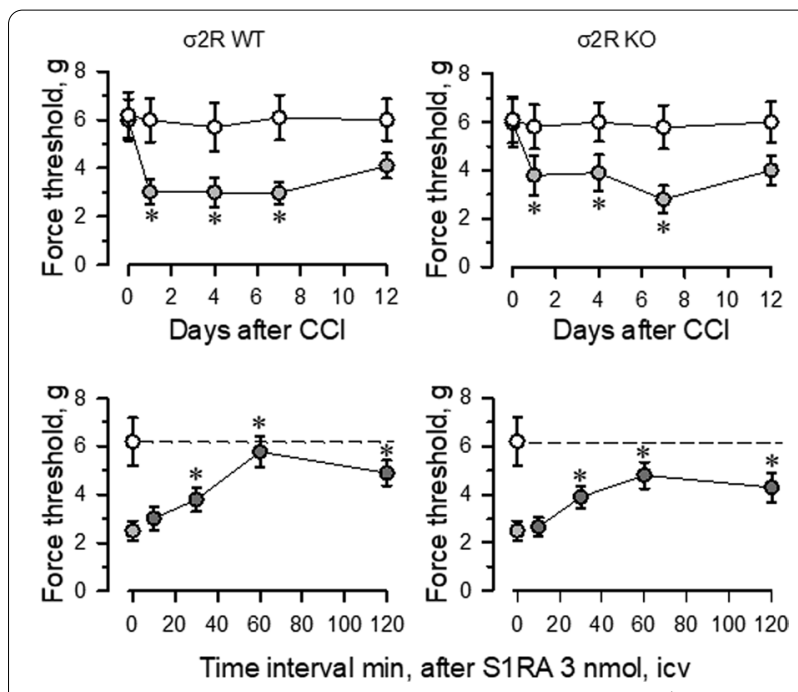

Fig. 2 Induction of mechanical allodynia in WT and $\sigma 2 \mathrm{R}^{-/-}$mice. Chronic constriction injure (CCI) of the sciatic nerve caused neuropathic pain in mice. The paw withdrawal thresholds of the contralateral and ipsilateral paw of the wild-type (WT; left panel) and knockout ( $\mathrm{KO}$; right panel) mice were measured before (indicated as 0 ) and 1, 4, 7, and 12 days after surgery. The force (in grams) at which the mice withdrew their paws in response to von Frey hair stimulation was determined as an index of mechanical allodynia. All data are presented as the mean \pm SEM of six mice. ${ }^{*}$ Indicates significantly different compared to the nociceptive threshold of the sham-operated control group on day 0 (7th after surgery); $p<0.05$. Lower panels: the effect of the $\sigma 1 R$ antagonist S1RA on the mechanical allodynia displayed by WT and $\sigma 2 R^{-1-}$ mice. Antiallodynic compound was administered icv 7 days after surgery, and the nociceptive threshold was evaluated at the indicated post-injection intervals (in minutes). The dashed line indicates the typical nociceptive threshold obtained of the contralateral paw. * Indicates significantly different compared to the ipsilateral paw; all data were analyzed by pairwise Holm-Sidak multiple comparison tests following ANOVA; $p<0.05$

effect peaked approximately $30 \mathrm{~min}$ after injection and decreased after $120 \mathrm{~min}$. The effect of morphine in $\sigma 2 \mathrm{R}^{-1-}$ mice was significantly lower than in WT animals (Fig. 3a). The apparent ED50 of icv-administered morphine was $4.84 \mathrm{nmol}$ (95\% confidence interval: 3.63-6.43) for control mice and $22.10 \mathrm{nmol}(19.34-24.72)$ for $\sigma 2 \mathrm{R}^{-1-}$ mice (Fig. 3b). Basal latencies were not different between $\sigma 2 \mathrm{R}^{-/-}$mice and WT mice $(1.61 \pm 0.14$ and $1.74 \pm 0.13$, respectively; $\mathrm{n}=10$ ).

Antisense oligodeoxynucleotides are useful tools for reducing neural protein expression, and their selectivity in terms of related signaling proteins has been described elsewhere $[26,31]$. We observed that the response of $\sigma 2 \mathrm{R}^{-/-}$mice and $\sigma 2 \mathrm{R}$ knockdown mice to morphine were identically decreased (Fig. 3b). It is known that in naïve mice, the administration of S1RA increases morphine antinociception [22, 30]. The ED70 of icv morphine in our analgesic paradigm was $10 \mathrm{nmol}$ in WT mice and 

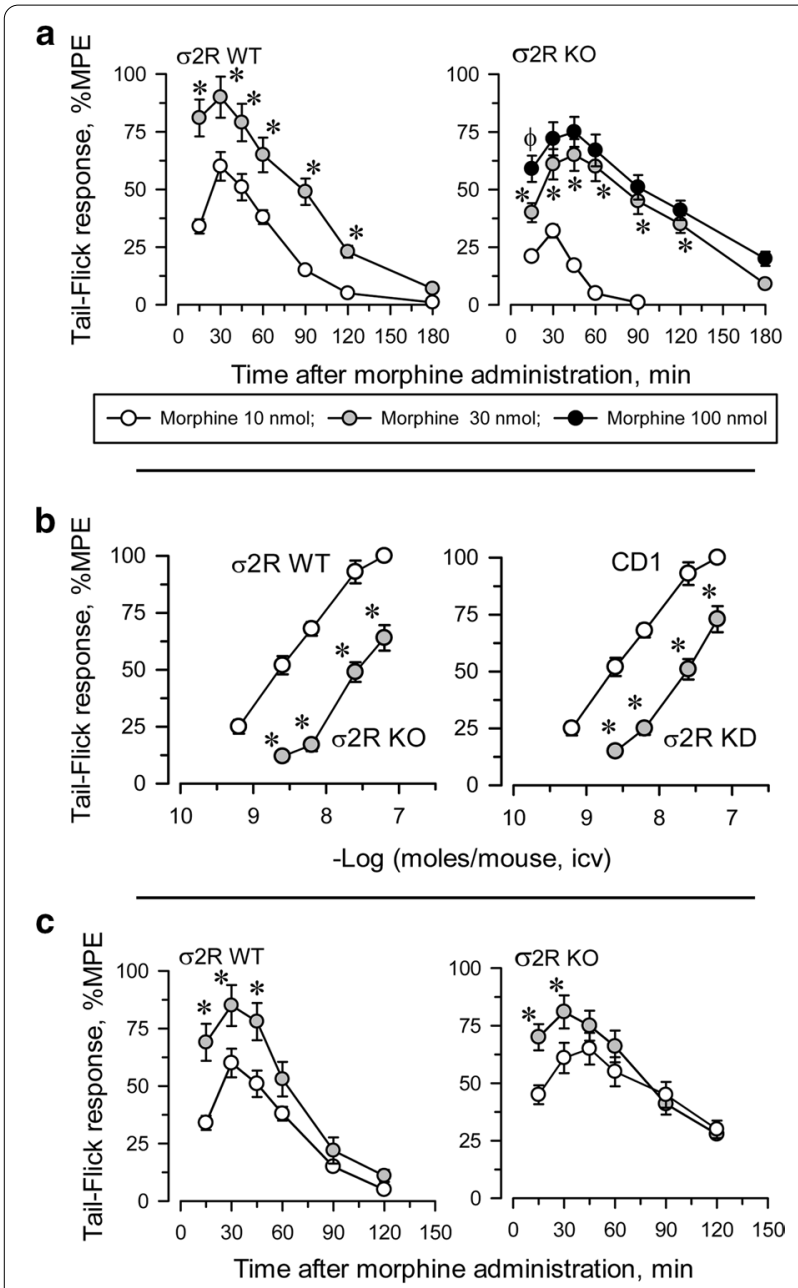

-O- Morphine; -O- S1RA + Morphine

Fig. $3 \sigma 2 R$ promotes morphine-induced supraspinal analgesia. a Wild-type (WT) and $\sigma 2 \mathrm{R}^{-/-}(\mathrm{KO})$ mice were icv injected with increasing doses of morphine, and antinociception was monitored at different intervals by the warm water $\left(52^{\circ} \mathrm{C}\right)$ tail-flick test. Each point is the mean \pm SEM of groups of six mice. For every post-opioid interval, ${ }^{*}$ indicates a significant difference compared to the group that received $10 \mathrm{nmol}$ morphine. $\mathbf{b}$ Dose response curves of morphine in WT, $\sigma 2 \mathrm{R}^{-/-}$mice (left panel) and of antisense oligonucleotide-induced $\sigma 2 R$ knockdown (KD) CD1 mice and controls treated with a mismatched oligodeoxinucleotide (RD-M; right panel). The analgesic effect was evaluated at point of the peak effect, i.e., $30 \mathrm{~min}$ after morphine injection. Each point is the mean \pm SEM of groups of six mice. ${ }^{*}$ Indicates a significant difference compared to the WT (RD-M) group. c Mice were icv injected with $3 \mathrm{nmol}$ S1RA 20 min before treatment with $10 \mathrm{nmol}$ (WT) or $30 \mathrm{nmol}$ (KO) morphine, and analgesia was evaluated 30 min later. The points are the mean \pm SEM of the data from six mice. For every postopioid interval, * indicates that S1RA produced a significantly different response than morphine only. All data were analyzed by pairwise Holm-Sidak multiple comparison tests following ANOVA; $p<0.05$

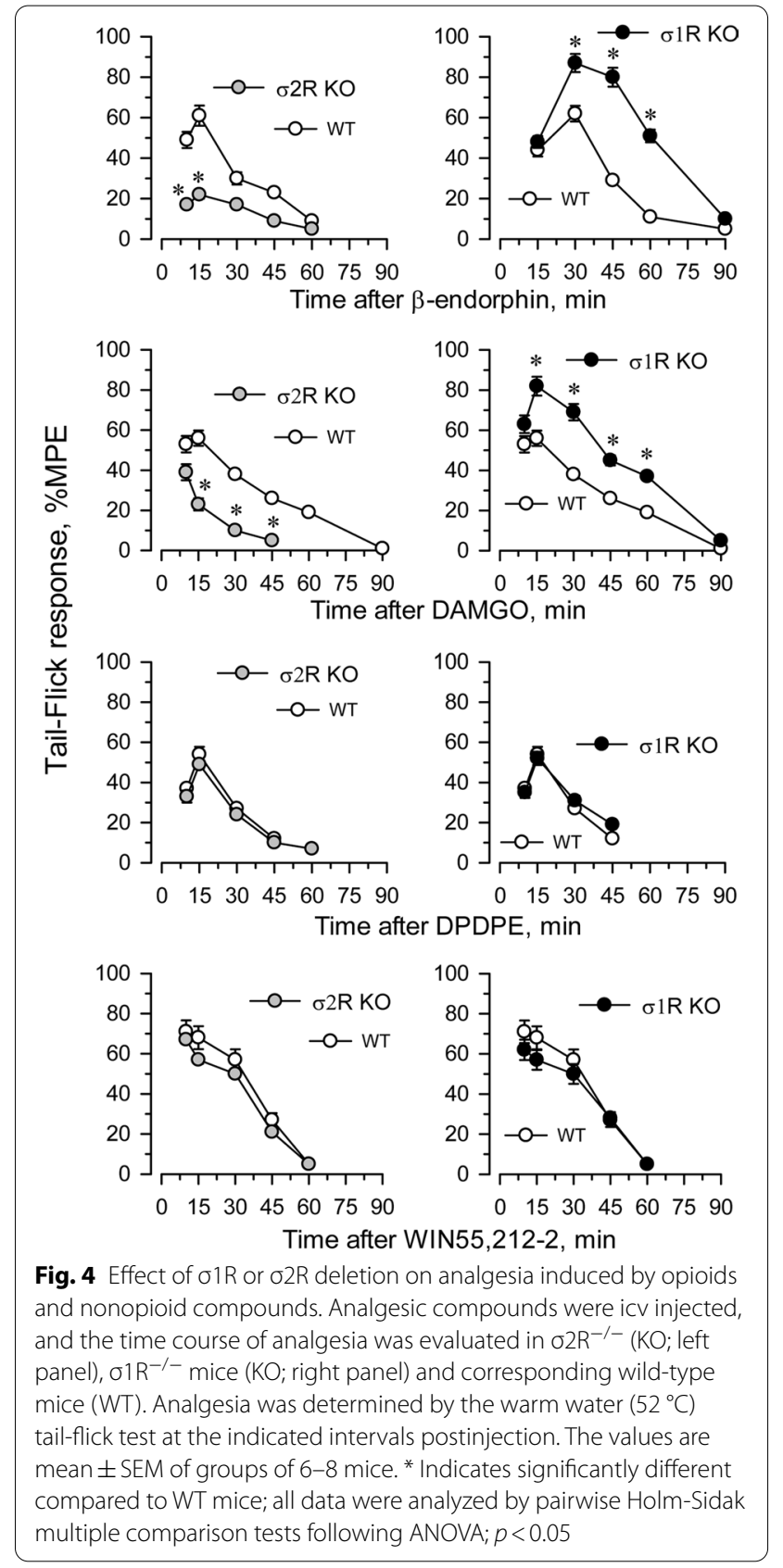

$30 \mathrm{nmol}$ in $\sigma 2 \mathrm{R}^{-l-}$ mice. Icv administered S1RA (3 nmol) increased the analgesic activity of morphine in both groups of mice (Fig. 3c).

The influence of targeted deletion of $\sigma 1 R$ gene on MORinduced antinociception is a known issue [22]. While the antinociceptive effects of DAMGO and $\beta$-endorphin were diminished in $\sigma 2 \mathrm{R}^{-/-}$mice, they were increased in $\sigma 1 \mathrm{R}^{-1-}$ mice (Fig. 4). The ability of these $\sigma$ receptors to regulate analgesia promoted by activation of $\mathrm{G}$ receptors other than MOR was explored. The deletion of either 
form of $\sigma$ receptor did not alter the analgesic activity of representative agonists of other G-receptors implicated in analgesia, such as the delta opioid receptor (DOR) agonist DPDPE, the cannabinoid receptor type 1 (CB1R) agonist WIN55,212-2 (Fig. 4) and the $\alpha 2$-adrenergic receptor $(\alpha 2 \mathrm{AR})$ agonist clonidine (not shown).

The influence of $\sigma 2 \mathrm{R}$ on the production of opioidinduced acute tolerance was also investigated. Mice received either saline (control) or morphine, and $24 \mathrm{~h}$ later, the analgesia evoked by a second injection of morphine was evaluated. Since mice showed a low analgesic response to morphine, to obtain comparable analgesic effects in both experimental groups, the dose of morphine administered to the $\sigma 2 \mathrm{R}^{-1-}$ mice was increased to promote approximately $80 \%$ of the maximum possible effect (MPE) in our paradigm. A priming dose of morphine was icv injected into WT $(10 \mathrm{nmol})$ and $\sigma 2 \mathrm{R}^{-1-}$ mice $(30 \mathrm{nmol})$, and the effect of their respective morphine ED80s was evaluated $24 \mathrm{~h}$ later. In WT mice, the analgesic effect of the ED80 decreased from $86 \pm 5 \%$ MPE to $42 \pm 4 \%$ MPE $24 \mathrm{~h}$ after the priming dose of $10 \mathrm{nmol}$ morphine. Deletion of $\sigma 2 \mathrm{R}$ did not prevent the development of acute tolerance, and ED80 antinociception dropped from about $75 \pm 5 \%$ to $26 \pm 4 \% \mathrm{MPE}$ (Fig. 5).

\section{Discussion}

Because there are currently no reliable antibodies (with sensitivity and selectivity) testing the $\sigma 2 \mathrm{R}$ protein in neuronal tissue, PCR was used to confirm the absence of $\sigma 2 R$ mRNA in the knockout animals provided by UC Davis KOMP Repository. $\sigma 2 \mathrm{R}^{-1-}$ mice showed exploratory behavior, locomotor performance, motor coordination and cognitive abilities comparable to those of WT mice. Furthermore, like naïve WT mice, naïve $\sigma 2 \mathrm{R}^{-1-}$ mice responded to a wide range of mechanical stimulus

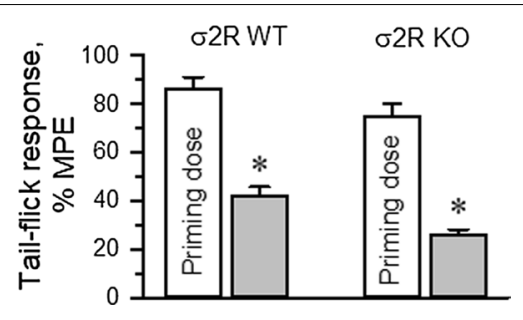

Fig. 5 Development of single-dose morphine-induced tolerance. The $\sigma 2 \mathrm{R}^{-1-}(\mathrm{KO})$ mice developed a profound and lasting tolerance to acute administration of morphine $(10 \mathrm{nmol}, \mathrm{icv})$. The data are expressed as the mean \pm SEM. ${ }^{*}$ Indicates significantly different compared to the effects induced by the morphine priming dose (30 min) in wild-type (WT) and $\sigma 2 \mathrm{R}^{-1-}$ mice; all data were analyzed by pairwise Holm-Sidak multiple comparison tests following ANOVA; $p<0.05$ intensities (from innocuous to noxious). Consequently, targeted deletion of the $\sigma 2 R$ gene did not affect normal mechanical stimulus perception or the motor response necessary to produce paw withdrawal. Nerve-injured WT and $\sigma 2 \mathrm{R}^{-1-}$ mice subjected to CCI showed similar levels of allodynia on day 7 after surgery. Then, the absence of the $\sigma 2 R$ receptor did not lead to significant alterations in the pathogenesis of neuropathic pain.

Several studies have demonstrated that $\sigma 1 \mathrm{R}^{-1-}$ mice do not develop allodynia in different animal models of neuropathic pain such as CCI [33], paclitaxel [34], spinal cord contusion injury [35], or spare nerve injury [36]. Accordingly, $\sigma 1 \mathrm{R}$ antagonists reduce nerve injuryinduced mechanical hypersensitivity in WT mice [30, 32]. Consistent with this idea, we observed that administration of the selective $\sigma 1 \mathrm{R}$ antagonist S1RA reduced allodynia in WT and $\sigma 2 \mathrm{R}^{-1-}$ mice. On the other hand, molecules that bind to $\sigma 2 \mathrm{R} / \mathrm{Tmem} 97$ as putative agonists reduce mechanical hypersensitivity in a spared nerve injury model with a duration of action and potency that is superior to that of gabapentin [20]. Thus, $\sigma 2 R$ activation or $\sigma 1 \mathrm{R}$ antagonists may promote comparable antiallodynic effects, which suggests that both types of $\sigma$ Rs are involved in regulating neuropathic pain but have opposing effects.

Interestingly, our study suggests that $\sigma 2 \mathrm{R}$ is involved in the analgesic effects of MOR agonists such as morphine, DAMGO and $\beta$-endorphin. In initial experiments, no differences in baseline latencies were observed among the WT $\left(\sigma 2 \mathrm{R}^{+/+}\right)$, heterozygous $\left(\sigma 2 \mathrm{R}^{+/-}\right)$, and homozygous $\left(\sigma 2 \mathrm{R}^{-I-}\right)$ groups in the warm-water tail-flick test for analgesia. Therefore, the absence of a functional $\sigma 2 R$ did not alter thermal nociception. However, the antinociceptive effects of morphine were impaired in $\sigma 2 \mathrm{R}^{-1-}$ mice; the ED50 was $5 \mathrm{nmol}$ in WT mice but more than $20 \mathrm{nmol}$ in mice lacking $\sigma 2 \mathrm{R}$. To explore the possibility that phenotypic modifications exhibited by $\sigma 2 \mathrm{R}^{-/-}$mice are a consequence of compensatory mechanisms assuming the physiological functions of $\sigma 2 \mathrm{R}$, we analyzed the expression of proteins implicated in the processes evaluated in our study. The mRNA expression levels of $\sigma 1 \mathrm{R}$, HINT1 and MOR were similar in WT and $\sigma 2 \mathrm{R}^{-1-}$ mice. Most importantly, treatment with oligos to reduce the expression of $\sigma 2 \mathrm{R}$ mRNA diminished the responses of the mice to levels similar to those of $\sigma 2 \mathrm{R}^{-1-}$ mice. Because oligo treatment promotes temporary reductions in target proteins, it is unlikely that compensatory changes resulting from the absence of this protein caused the diminished response of $\sigma 2 \mathrm{R}^{-/-}$mice to morphine.

Thus, our study suggest that $\sigma 2 \mathrm{R}$ is essential for the antinociceptive effects of exogenous and endogenous ligands of MOR but not for the antinociceptive effects of other families of G-receptors that also mediate analgesia, 
such as DOR, CB1R and $\alpha 2 A R$. $\sigma 2 R$ likely plays a relevant role in the regulation of MOR-mediated analgesia, sharing a physiological function with $\sigma 1 \mathrm{R}$ and glutamate $N$-methyl-D-aspartate receptor (NMDAR). The cytosolic C-terminus of MOR binds to the HINT1 protein, facilitating the interactions of $\sigma 1 \mathrm{R}$ and NMDAR with the MOR [22]. Notably, a lack of $\sigma 2 R$ did not interfere with the beneficial effects of the selective $\sigma 1 R$ antagonist S1RA on MOR-mediated analgesia. MOR agonists such as morphine increase the activity of NMDARs and then trigger a negative feedback on MOR signaling. S1RA promotes the inhibition of NMDARs by removing the $\sigma 1 \mathrm{R}$ from NMDAR NR1 subunits facilitating the binding of its inhibitor, calcium-activated calmodulin [22, 37]. As a result, morphine analgesia is increased and the perception of neuropathic pain is diminished [22]. As expected, this regulatory mechanism is absent in $\sigma 1 \mathrm{R}^{-1-}$ mice [37], but our study showed that deletion of $\sigma 2 R$ preserved the enhancement of morphine analgesia induced by S1RA. Thus, disruption of $\sigma 1 \mathrm{R}$-mediated negative control of NMDARs on MOR activity seems to account for the enhancement of the antinociceptive effects of clinically relevant opioids such as morphine, fentanyl, oxycodone, codeine, buprenorphine, and tramadol [21, 38]. Accordingly, morphine shows an enhanced capacity to produce antinociception in $\sigma 1 \mathrm{R}^{-/-}$mice; $3 \mathrm{nmol}$ morphine produces the same antinociceptive effect in $\sigma 1 \mathrm{R}^{-1-}$ mice as $10 \mathrm{nmol}$ morphine does in WT mice [22]. We report here that deletion of $\sigma 1 \mathrm{R}$ or $\sigma 2 \mathrm{R}$ mostly affects MOR function but does not alter antinociception promoted by either DOR or CB1R agonists. Therefore, while $\sigma 1 R$ inhibits and $\sigma 2 R$ facilitates MOR-mediated analgesia these receptors exchange their roles when regulating neuropathic pain perception. Our study may open new avenues for the identification of pharmacological targets for diminishing pain perception and improving handling of opioid detoxification therapies.

\begin{abstract}
Abbreviations
a2AR: a2-Adrenergic receptor; б1R: Sigma-1 receptor; o2R: Sigma-2 receptor: CB1R: Cannabinoid receptor type 1; CCl: Chronic sciatic nerve constriction injury; DAMGO: [D-Ala, N-MePhe, Gly-ol]-encephalin; DOR: Delta opioid receptor; DPDPE: [D-Pen2,5]-encephalin; HINT1: Histidine triad nucleotidebinding protein 1; KO (-/-): Knockout; MOR: Mu-opioid receptor; NMDAR: N-Methyl-D-aspartate receptor; ODN: Phosphorothioate antisense oligodeoxynucleotides; PGRMC1: Progesterone receptor membrane component 1; S1RA: 4-[2-[[5-Methyl-1-(2-naphthalenyl)-1H-pyrazol-3-yl]oxy]ethyl] morpholine; TMEM97:Transmembrane receptor 97; WT: Wild type.
\end{abstract}

\section{Acknowledgements}

We would like to thank Gabriela de Alba, and María José López for their excellent technical assistance.

\section{Authors' contributions}

Conceptualization: JG, PSB and MM; Methodology: PSB, JG and ECM; Investigation: PSB, ECM and MRM; Writing (draft, review and editing): JG, PSB and MM; Funding acquisition: JG. All authors read and approved the final manuscript.
Funding

This work was supported by MICINN Plan Nacional I + D + i [Grant number RT 2018-093677-B-100]. EC-M was supported by a Grant from MECD [FPU 15/02356].

\section{Availability of data and materials}

The data and materials of the manuscript are available upon reasonable request.

\section{Ethics approval and consent to participate}

All procedures involving animals were approved by the Spanish government and in accordance with the guidelines of the European Communities Council Directives.

\section{Consent for publication}

All the authors consented to be an author of this publication.

\section{Competing interests}

The authors declare that all the research presented here was conducted in the absence of any commercial or financial relationships that could be construed as a potential conflict of interest.

\section{Author details}

${ }^{1}$ Neuropharmacology, Cajal Institute, Consejo Superior de Investigaciones Científicas (CSIC), Doctor Arce 37, 28002 Madrid, Spain. ${ }^{2}$ Drug Discovery \& Preclinical Development, Esteve, Barcelona, Spain.

Received: 16 July 2020 Accepted: 22 September 2020

Published online: 11 November 2020

\section{References}

1. Bowen WD. Sigma receptors: recent advances and new clinical potentials. Pharm Acta Helv 2000:74:211-8.

2. Matsumoto RR. Targeting sigma receptors: novel medication development for drug abuse and addiction. Expert Rev Clin Pharmacol. 2009;2:351-8.

3. Schmidt HR, Kruse AC. The molecular function of sigma receptors: past, present, and future. Trends Pharmacol Sci. 2019;40:636-54.

4. Walker JM, Bowen WD, Walker FO, Matsumoto RR, De CB, Rice KC. Sigma receptors: biology and function. Pharmacol Rev. 1990;42:355-402.

5. Martin WR, Eades CG, Thompson JA, Huppler RE, Gilbert PE. The effects of morphine- and nalorphine- like drugs in the nondependent and morphine-dependent chronic spinal dog. J Pharmacol Exp Ther. 1976;197:517-32

6. Abate C, Niso M, Berardi F. Sigma-2 receptor: past, present and perspectives on multiple therapeutic exploitations. Future Med Chem 2018;10:1997-2018

7. Maurice T, Su TP. The pharmacology of sigma-1 receptors. Pharmacol Ther. 2009;124:195-206.

8. Rousseaux CG, Greene SF. Sigma receptors [sigmaRs]: biology in normal and diseased states. J Recept Signal Transduct Res. 2016;36:327-88.

9. Hanner M, Moebius FF, Flandorfer A, Knaus HG, Striessnig J, Kempner E, et al. Purification, molecular cloning, and expression of the mammalian sigma1-binding site. Proc Natl Acad Sci U S A. 1996;93:8072-7.

10. Alon A, Schmidt HR, Wood MD, Sahn JJ, Martin SF, Kruse AC. Identification of the gene that codes for the sigma2 receptor. Proc Natl Acad Sci USA. 2017:114:7160-5.

11. Hiranita T. Identification of the Sigma-2 Receptor: Distinct from the Progesterone Receptor Membrane Component 1 (PGRMC1). J Alcohol Drug Depend. 2016;4.

12. Kim FJ, Pasternak GW. Cloning the sigma2 receptor: Wandering 40 years to find an identity. Proc Natl Acad Sci USA. 2017;114:6888-900.

13. Bartz F, Kern L, Erz D, Zhu M, Gilbert D, Meinhof T, et al. Identification of cholesterol-regulating genes by targeted RNAi screening. Cell Metab. 2009:10:63-75.

14. Vilner BJ, Bowen WD. Modulation of cellular calcium by sigma-2 receptors: release from intracellular stores in human SK-N-SH neuroblastoma cells. J Pharmacol Exp Ther. 2000;292:900-11. 
15. Huang YS, Lu HL, Zhang $\sqcup$, Wu Z. Sigma-2 receptor ligands and their perspectives in cancer diagnosis and therapy. Med Res Rev. 2014;34:532-66.

16. Mach $\mathrm{RH}$, Zeng $\mathrm{C}$, Hawkins WG. The sigma2 receptor: a novel protein for the imaging and treatment of cancer. J Med Chem. 2013;56:7137-60.

17. van Waarde A, Rybczynska AA, Ramakrishnan NK, Ishiwata K, Elsinga PH, Dierckx RA. Potential applications for sigma receptor ligands in cancer diagnosis and therapy. Biochim Biophys Acta. 2015;1848:2703-14.

18. Vazquez-Rosa E, Watson MR, Sahn JJ, Hodges TR, Schroeder RE, CintronPerez CJ, et al. Neuroprotective Efficacy of a Sigma 2 Receptor/TMEM97 Modulator (DKR-1677) after Traumatic Brain Injury. ACS Chem Neurosci. 2019;10:1595-602.

19. Yi B, Sahn JJ, Ardestani PM, Evans AK, Scott LL, Chan JZ, et al. Small molecule modulator of sigma 2 receptor is neuroprotective and reduces cognitive deficits and neuroinflammation in experimental models of Alzheimer's disease. J Neurochem. 2017;140:561-75.

20. Sahn JJ, Mejia GL, Ray PR, Martin SF, Price TJ. Sigma 2 Receptor/Tmem97 Agonists Produce Long Lasting Antineuropathic Pain Effects in Mice. ACS Chem Neurosci. 2017;8:1801-11.

21. Mei J, Pasternak GW. Sigma1 receptor modulation of opioid analgesia in the mouse. J Pharmacol Exp Ther. 2002:300:1070-4.

22. Rodríguez-Muñoz M, Sánchez-Blázquez P, Herrero-Labrador R, MartínezMurillo R, Merlos M, Vela JM, et al. The sigma1 receptor engages the redox-regulated HINT1 protein to bring opioid analgesia under NMDA receptor negative control. Antioxid Redox Signal. 2015;22:799-818.

23. Sánchez-Blázquez P, Pozo-Rodrigalvarez A, Merlos M, Garzón J. The Sigma-1 Receptor Antagonist, S1RA, Reduces Stroke Damage, Ameliorates Post-Stroke Neurological Deficits and Suppresses the Overexpression of MMP-9. Mol Neurobiol. 2018;55:4940-51.

24. Garzón J, Herrero-Labrador R, Rodríguez-Muñoz M, Shah R, VicenteSánchez A, Wagner CR, et al. HINT1 protein: a new therapeutic target to enhance opioid antinociception and block mechanical allodynia. Neuropharmacology. 2015;89:412-23.

25. Bennett GJ, Xie YK. A peripheral mononeuropathy in rat that produces disorders of pain sensation like those seen in man. Pain. 1988;33:87-107.

26. Sánchez-Blázquez P, García-España A, Garzón J. In vivo injection of antisense oligodeoxynucleotides to $\mathrm{G}$ alpha subunits and supraspinal analgesia evoked by mu and delta opioid agonists. J Pharmacol Exp Ther. 1995:275:1590-6.

27. Riad A, Zeng C, Weng CC, Winters H, Xu K, Makvandi M, et al. Sigma-2 Receptor/TMEM97 and PGRMC-1 Increase the Rate of Internalization of LDL by LDL Receptor through the Formation of a Ternary Complex. Sci Rep. 2018;8:16845.

28. Sánchez-Blázquez P, García-España A, Garzón J. Antisense oligodeoxynucleotides to opioid mu and delta receptors reduced morphine dependence in mice: role of delta-2 opioid receptors. J Pharmacol Exp Ther. 1997;280:1423-31.
29. Sánchez-Blázquez P, Rodríguez-Muñoz M, Berrocoso E, Garzón J. The plasticity of the association between mu-opioid receptor and glutamate ionotropic receptor $\mathrm{N}$ in opioid analgesic tolerance and neuropathic pain. Eur J Pharmacol. 2013;716:94-105.

30. Romero L, Zamanillo D, Nadal X, Sanchez-Arroyos R, Rivera-Arconada I, Dordal A, et al. Pharmacological properties of S1RA, a new sigma-1 receptor antagonist that inhibits neuropathic pain and activity-induced spinal sensitization. Br J Pharmacol. 2012;166:2289-306.

31. Garzón J, Rodríguez-Muñoz M, López-Fando A, Sánchez-Blázquez P. The RGSZ2 protein exists in a complex with mu-opioid receptors and regulates the desensitizing capacity of Gz proteins. Neuropsychopharmacology. 2005;30:1632-48.

32. Roh DH, Kim HW, Yoon SY, Seo HS, Kwon YB, Kim KW, et al. Intrathecal injection of the sigma(1) receptor antagonist BD1047 blocks both mechanical allodynia and increases in spinal NR1 expression during the induction phase of rodent neuropathic pain. Anesthesiology. 2008;109:879-89.

33. de la Puente B, Nadal X, Portillo-Salido E, Sánchez-Arroyos R, Ovalle S, Palacios $G$, et al. Sigma-1 receptors regulate activity-induced spinal sensitization and neuropathic pain after peripheral nerve injury. Pain. 2009;145:294-303.

34. Nieto FR, Cendán CM, Sánchez-Fernández C, Cobos EJ, Entrena JM, Tejada MA, et al. Role of sigma-1 receptors in paclitaxel-induced neuropathic pain in mice. J Pain. 2012;13:1107-21.

35. Castany S, Gris G, Vela JM, Verdu E, Boadas-Vaello P. Critical role of sigma-1 receptors in central neuropathic pain-related behaviours after mild spinal cord injury in mice. Sci Rep. 2018:8:3873.

36. Bravo-Caparros I, Perazzoli G, Yeste S, Cikes D, Baeyens JM, Cobos EJ, et al. Sigma-1 Receptor Inhibition Reduces Neuropathic Pain Induced by Partial Sciatic Nerve Transection in Mice by Opioid-Dependent and -Independent Mechanisms. Front Pharmacol. 2019;10:613.

37. Rodríguez-Muñoz M, Cortés-Montero E, Pozo-Rodrigalvarez A, SánchezBlázquez P, Garzón-Niño J. The ON:OFF switch, sigma1R-HINT1 protein, controls GPCR-NMDA receptor cross-regulation: implications in neurological disorders. Oncotarget. 2015;6:35458-777.

38. Diaz JL, Zamanillo D, Corbera J, Baeyens JM, Maldonado R, Pericas MA, et al. Selective sigma-1 (sigma1) receptor antagonists: emerging target for the treatment of neuropathic pain. Cent Nerv Syst Agents Med Chem. 2009;9:172-83.

\section{Publisher's Note}

Springer Nature remains neutral with regard to jurisdictional claims in published maps and institutional affiliations.
Ready to submit your research? Choose BMC and benefit from:

- fast, convenient online submission

- thorough peer review by experienced researchers in your field

- rapid publication on acceptance

- support for research data, including large and complex data types

- gold Open Access which fosters wider collaboration and increased citations

- maximum visibility for your research: over $100 \mathrm{M}$ website views per year

At BMC, research is always in progress.

Learn more biomedcentral.com/submissions 